


\section{Proficiency test for dioxins, dioxin-like PCBs and non-dioxin-like PCBs in feed oil}

I.J.W. Elbers, G. ten Dam, D.P.K.H. Pereboom, W.C.M. de Nijs

This research has been carried out by RIKILT Wageningen University \& Research, institute within the legal entity Wageningen Research Foundation funded by the Dutch Ministry of Agriculture, Nature and Food Quality WOT-02-004-004.

Wageningen, November 2018

RIKILT report 2018.007 (version 2) 
Elbers, I.J.W., G. ten Dam, D.P.K.H. Pereboom, W.C.M. de Nijs, 2018. Proficiency test for dioxins, dioxin-like PCBs and non-dioxin-like PCBs in feed oil. Wageningen, RIKILT Wageningen University \& Research, RIKILT report 2018.007 (version 2). 24 pp.; 0 fig.; 7 tab.; 13 ref.

Project number: 1227248801

Project title: Borging private laboratoria (WOT-02-004-004)

Coordinator proficiency tests: Diana Pereboom and Ingrid Elbers

Dioxin researcher: Guillaume ten Dam

Project leader: Monique de Nijs

This report can be downloaded for free at https://doi.org/10.18174/462577 or at www.wur.eu/rikilt (under RIKILT publications).

(C) 2018 RIKILT Wageningen University \& Research, institute within the legal entity Wageningen Research Foundation. Hereinafter referred to as RIKILT.

The client is allowed to publish or distribute the full report to third parties. Without prior written permission from RIKILT it is not allowed to:

a) publish parts of this report;

b) use this report or title of this report in conducting legal procedures, for advertising, acquisition or other commercial purposes;

c) use the name of RIKILT other than as the author of this report.

P.O. Box 230, 6700 AA Wageningen, The Netherlands, T +31(0)317 4802 56, E info.RIKILT@wur.nl, www.wur.eu/rikilt. RIKILT is part of Wageningen University \& Research.

This report from RIKILT has been produced with the utmost care. However, RIKILT does not accept liability for any claims based on the contents of this report.

RIKILT report 2018.007 (version 2)

Version 2: Erratum for last sentence in Chapter 5: lab PT189 should be PT188 and PT191 should be PT190.

This report replaces report 2018.007.

Distribution list:

- 20 participating European laboratories 


\section{Contents}

$\begin{array}{ll}\text { Summary } & 5\end{array}$

1

$\begin{array}{ll}\text { Introduction } & 7\end{array}$

2

$\begin{array}{ll}\text { Material en methods } & 8\end{array}$

2.1 Material preparation $\quad 8$

2.2 Sample identification $\quad 8$

2.3 Participants $\quad 8$

2.4 Homogeneity and stability study $\quad 9$

2.5 Sample distribution and instructions $\quad 9$

3

$\begin{array}{ll}\text { Statistical evaluation } & 10\end{array}$

$\begin{array}{lll}3.1 & \text { Calculation of the consensus value }(X) & 10\end{array}$

3.2 Calculation of the uncertainty of the assigned value $(u) \quad 10$

3.3 Calculation of the standard deviation for proficiency assessment $\left(\sigma_{P}\right) \quad 11$

$\begin{array}{lll}3.4 & \text { Performance characteristics with regard to the accuracy } & 11\end{array}$

4

Results

References

$\begin{array}{lll}\text { Annex } 1 & \text { Codification of the samples } & 18\end{array}$

Annex 2 Statistical evaluation of homogeneity data 19

$\begin{array}{lll}\text { Annex } 3 & \text { Instruction letter } & \mathbf{2 1}\end{array}$

Annex 4 Overview of the applied methods for dioxins and (non)dioxin-like PCBs 



\section{Summary}

In January 2018 a proficiency test for dioxins, dioxin-like and non-dioxin-like PCBs in oils and fatty acids used as feed materials was organized by RIKILT Wageningen University \& Research. This PT-test enabled laboratories to evaluate their competence for the analysis of dioxins, dioxin-like and nondioxin-like PCBs in feed oil and was carried under accreditation according to ISO/IEC 17043 (R013 at www.rva.nl).

For this proficiency test, three test materials were prepared:

- Material A: sunflower oil containing dioxins/PCBs aimed at (relative to a feed with a moisture content of $12 \%)$ :

- $1.46 \mathrm{ng} / \mathrm{kg}$ WHO-PCDD/F and dl-PCB-TEQ (ub)

- $0.34 \mathrm{ng} / \mathrm{kg}$ WHO-DL-PCB-TEQ (ub)

$-1.1 \mathrm{ng} / \mathrm{kg}$ WHO-PCDD/F-TEQ (ub)

- $8.4 \mu \mathrm{g} / \mathrm{kg}$ total NDL-PCB (ub)

- Material B: sunflower oil mixed with fish oil containing dioxins/PCBs aimed at (relative to a feed with a moisture content of $12 \%$ ):

- $1.17 \mathrm{ng} / \mathrm{kg}$ WHO-PCDD/F and dl-PCB-TEQ (ub)

$-0.76 \mathrm{ng} / \mathrm{kg}$ WHO-DL-PCB-TEQ (ub)

$-0.41 \mathrm{ng} / \mathrm{kg}$ WHO-PCDD/F-TEQ (ub)

- $24 \mu \mathrm{g} / \mathrm{kg}$ total NDL-PCB (ub)

- Material C: rapeseed free fatty acids containing dioxins/PCBs aimed at (relative to a feed with a moisture content of $12 \%)$ :

- $1.41 \mathrm{ng} / \mathrm{kg}$ WHO-PCDD/F and dl-PCB-TEQ (ub)

$-0.59 \mathrm{ng} / \mathrm{kg}$ WHO-DL-PCB-TEQ (ub)

$-0.82 \mathrm{ng} / \mathrm{kg}$ WHO-PCDD/F-TEQ (ub)

$-9.8 \mu \mathrm{g} / \mathrm{kg}$ total NDL-PCB (ub)

During homogeneity testing, all materials proved to be sufficiently homogenous for proficiency testing.

Twenty laboratories subscribed for participation in this test. One participant was unable to report results.

A total of 2091 z-scores were calculated to assess the performance of the participating laboratories. With regard to the accuracy $9 \%$ of the z-scores were outside the range -2 to 2 .

Of the 19 reporting participants, $11 \%$ of the participants reported satisfactory results for all values (sum-values and individual compounds). Another $53 \%$ of the participants reported satisfactory results for the sum-values. 


\section{Introduction}

Proficiency testing is conducted to provide laboratories with a powerful tool to evaluate and demonstrate the reliability of the data that is produced. Next to validation and accreditation, proficiency testing is an important requirement of the EU Additional Measures Directive 93/99/EEC [1] and is required by ISO 17025:2005 [2].

The aim of this proficiency test was to give laboratories the possibility to evaluate or demonstrate their competence for the analysis of dioxins, dioxin-like and non-dioxin-like PCBs according to Commission Regulation 152/2009 [13]. The preparation of the materials, including the suitability testing of the materials and the evaluation of the quantitative results were carried out under accreditation (R013 at www.rva.nl) according to ISO 17043 [3]. 


\section{Material en methods}

This proficiency test focused on dioxins and (non)dioxin-like PCBs which are regulated in feed in the EU [4]. The maximum levels and action thresholds for oils originating from plants are presented in Table 1.

Table 1 Maximum levels and action thresholds in feed oil of the compounds included in the proficiency test [4] related to a feed with a moisture content of $12 \%$.

\begin{tabular}{lcc} 
Compound & Maximum level & Action threshold \\
Dioxins in pg TEQ/g & 0.75 & 0.5 \\
\hline Dioxin-like PCBs in pg TEQ/g & - & 0.5 \\
\hline Dioxins and dioxin-like PCBs in pg TEQ/g & 1.5 & - \\
\hline Non-dioxin-like PCBs in ng/g & 10 & - \\
\hline
\end{tabular}

\subsection{Material preparation}

Material A was prepared by mixing contaminated sunflower oil with standard solutions of several PCBs and blank sunflower oil.

Material B was prepared by mixing contaminated fish oil with blank sunflower oil and with PCB153. Material $C$ was prepared by mixing an extract of a contaminated soil sample with rape seed oil. Target contamination levels are presented in Table 2. Each of the materials was homogenized according to in-house standard operating procedures [5].

Table 2 Target contamination levels of dioxins and (non)dioxin-like PCBs in the proficiency test materials.

\begin{tabular}{lcccc} 
Material & \multicolumn{3}{c}{ Target amount } \\
\cline { 2 - 5 } code & PCDD/F-TEQ ub & dl-PCB-TEQ ub & PCDD/F-PCB-TEQ ub & Total NDL-PCBs ub \\
A & $1.1 \mathrm{ng} / \mathrm{kg}$ & $0.34 \mathrm{ng} / \mathrm{kg}$ & $1.46 \mathrm{ng} / \mathrm{kg}$ & $8.4 \mu \mathrm{kg} / \mathrm{kg}$ \\
\hline $\mathrm{B}$ & $0.76 \mathrm{ng} / \mathrm{kg}$ & $0.76 \mathrm{ng} / \mathrm{kg}$ & $1.17 \mathrm{ng} / \mathrm{kg}$ & $24 \mu \mathrm{kg}$ \\
\hline $\mathrm{C}$ & $0.59 \mathrm{ng} / \mathrm{kg}$ & $0.59 \mathrm{ng} / \mathrm{kg}$ & $1.41 \mathrm{ng} / \mathrm{kg}$ & $9.8 \mu \mathrm{kg} / \mathrm{kg}$ \\
\hline
\end{tabular}

\subsection{Sample identification}

After homogenization, the sample materials were divided into sub-portions of approximately 15 gram for material A and 10 gram for materials B and C and stored in brown glass containers. The samples for the participants were randomly selected and coded through a website application. For each laboratory one sample set was prepared consisting of one at random selected sample of each material. The codes of the samples belonging to each sample set are presented in Annex 1.

\subsection{Participants}

Twenty European laboratories subscribed for participation in the proficiency test. Each participant was asked to report the results through a web application designed for proficiency tests. 


\subsection{Homogeneity and stability study}

The homogeneity of the materials was tested according to The International Harmonized Protocol for Proficiency Testing of Analytical Laboratories [7] and ISO 13528 [8], taking into account the insights discussed by Thompson [9] regarding the Horwitz equation. With this procedure the between-sample standard deviation $\left(\mathrm{s}_{\mathrm{s}}\right)$ and the within-sample standard deviation $\left(\mathrm{s}_{\mathrm{w}}\right)$ are compared with the standard deviation for proficiency assessment derived from the Horwitz equation $\left(\sigma_{p}, \S 4.3\right)$. The method applied for homogeneity testing is considered suitable if $\mathrm{s}_{\mathrm{w}}<0.5^{*} \sigma_{\mathrm{p}}$ and a material is considered adequately homogeneous if $\mathrm{s}_{\mathrm{s}}<0.3^{*} \sigma_{\mathrm{p}}$.

Ten containers of each materials A, B and C were analysed in duplicate for PCB 153 to determine the homogeneity of the materials. The homogeneity of other compounds in the materials was not tested, because the homogeneity test of PCB 153 was considered adequate to prove the sufficient homogeneity of the material. The results of the homogeneity study and their statistical evaluation are presented in Annex 2. All three materials demonstrated to be sufficiently homogeneous for use in the proficiency test.

No stability tests were performed since dioxins, dioxin-like PCBs and non-dioxin-like PCBs are persistent and very stable compounds.

\subsection{Sample distribution and instructions}

Each of the participating laboratories received a randomly assigned laboratory code, generated by the website application. The sample sets with the corresponding number, consisting of three coded samples (Annex 1) were sent to the participating laboratories on January 29, 2018. The sample sets were packed in a carton box and were dispatched to the participants immediately by courier. The samples were accompanied by a letter (Annex 3 ) describing the requested analyses and an acknowledgement of receipt form. By e-mail the laboratories received instructions on how to use the web application to report results.

The laboratories were asked to store the samples until analysis according to their own laboratory procedure. A single analysis of each sample was requested. In addition, each participant was asked to report whether the sample exceeded the maximum levels and or thresholds.

The deadline for submitting the quantitative results was March 5, 2018, allowing five weeks for the analysis. 


\section{Statistical evaluation}

The statistical evaluation of the quantitative part of the study was carried out according to the International Harmonized Protocol for the Proficiency Testing of Analytical Laboratories [7], elaborated by ISO, IUPAC and AOAC and ISO 13528 [8] in combination with the insights published by the Analytical Methods Committee $[11,12]$ regarding robust statistics.

For the evaluation of the quantitative results the consensus value, the uncertainty of the consensus value, a standard deviation for proficiency assessment and z-scores were calculated.

\subsection{Calculation of the consensus value (X)}

The consensus value $(X)$ was determined using robust statistics $[8,11,12]$. The advantage of robust statistics is that all values are taken into account: outlying observations are retained, but given less weight. Furthermore, it is not expected to receive normally distributed data in a proficiency test. When using robust statistics, the data does not have to be normally distributed in contrast to conventional outlier elimination methods.

The robust mean of the reported results of all participants, calculated from an iterative process that starts at the median of the reported results using a cut-off value depending on the number of results, was used as the consensus value $[8,11]$. Results which were reported with smaller than values $\left({ }^{\prime}<\right.$ ') were changed to the corresponding detection limits.

\subsection{Calculation of the uncertainty of the assigned value (u)}

The uncertainty of the consensus value is calculated to determine the influence of this uncertainty on the evaluation of the laboratories. A high uncertainty of the consensus value will lead to a high uncertainty of the calculated participants $z_{a}$-scores. If the uncertainty of the consensus value and thus the uncertainty of the $z_{a}$-score is high, the evaluation could indicate unsatisfactory method performance without any cause within the laboratory. In other words, illegitimate conclusions could be drawn regarding the performance of the participating laboratories from the calculated $\mathrm{z}_{\mathrm{a}}$-scores if the uncertainty of the consensus value is not taken into account.

The uncertainty of the consensus value (the robust mean) is calculated from the estimation of the standard deviation of the consensus value and the number of values used for the calculation of the consensus value [8]:

$$
u=1.25 * \frac{\hat{\sigma}}{\sqrt{n}}
$$

where:

$\mathrm{u}=$ uncertainty of the consensus value;

$\mathrm{n}=$ number of values used to calculate the consensus value;

$\hat{\sigma}=$ the estimate of the standard deviation of the consensus value resulting from robust statistics.

According to ISO 13528 [8] the uncertainty of the consensus value (u) is negligible and therefore does not have to be included in the statistical evaluation if: 
$u \leq 0.3 \sigma_{\mathrm{p}}$

where:

$\mathrm{u}=$ The uncertainty of the consensus value;

$\sigma_{\mathrm{P}}=$ Standard deviation for proficiency assessment(§3.3).

In case the uncertainty of the consensus value does not comply with this criterion, the uncertainty of the consensus value should be taken into account when evaluating the performance of the participants regarding the accuracy (\$3.4). In case the uncertainty is $>0.7 \sigma_{\mathrm{p}}$ the calculated $z$-scores should not be used for evaluation of laboratories' performance and are presented for information only.

\subsection{Calculation of the standard deviation for proficiency assessment $\left(\sigma_{P}\right)$}

According to Commission Decision 2002/657/EC [6], the coefficient of variation for the repeated analysis of a reference or fortified material under reproducibility conditions, shall not exceed the level calculated by the Horwitz equation. The Horwitz equation, $\sigma_{H}=0.02 \mathrm{c}^{0.8495}$, presents a useful and widespread applied relation between the expected relative standard deviation of a singular analysis result under reproducibility conditions, and the concentration, $c(\mathrm{~g} / \mathrm{g})$. It expresses inter-laboratory precision expected in inter-laboratory trials. Therefore, this relation is suitable for calculating the standard deviation for proficiency assessment.

Thompson [7] demonstrated that the Horwitz equation is not applicable to the lower concentration range $(<120 \mu \mathrm{g} / \mathrm{kg})$. Therefore a complementary model is suggested:

For analyte concentrations $<120 \mu \mathrm{g} / \mathrm{kg}$ :

$\sigma_{\mathrm{P}}=0.22 \mathrm{C}$

where:

$\sigma_{\mathrm{P}}=$ standard deviation in proficiency assessment;

$c=$ concentration of the analyte expressed as dimensionless fraction

\subsection{Performance characteristics with regard to the accuracy}

For illustrating the performance of the participating laboratories with regard to the accuracy a $\mathrm{z}_{\mathrm{a}}$-score is calculated. For the evaluation of the performance of the laboratories, ISO 13528 [8] is applied.

According to these guidelines $\mathrm{z}_{\mathrm{a}}$-scores are classified as presented in Table 3.

Table 3 Classification of $z_{a}$-scores.

\begin{tabular}{cc}
\hline$\left|z_{a}\right| \leq 2$ & Satisfactory \\
\hline $2<\left|z_{a}\right|<3$ & Questionable \\
$\left|z_{a}\right| \geq 3$ & Unsatisfactory
\end{tabular}

If the calculated uncertainty of the consensus value complies with the criterion mentioned in $\S 4.2$, the uncertainty is negligible. In this case the accuracy z-score is calculated from:

$$
\mathrm{z}_{\mathrm{a}}=\frac{\mathrm{X}-\mathrm{X}}{\sigma_{\mathrm{p}}}
$$


where:

$\mathrm{z}_{\mathrm{a}}=$ accuracy $\mathrm{z}$-score;

$\bar{x}=$ result of the laboratory;

$\mathrm{X}=$ consensus value;

$\sigma_{\mathrm{P}}=$ standard deviation for proficiency assessment.

However, if the uncertainty of the consensus value does not comply with the criterion mentioned in $\S 3.2$, it could influence the evaluation of the laboratories. Although, according to ISO 13528 in this case no z-scores can be calculated, we feel that evaluation of the participating laboratories is of main importance justifying the participating laboratories' effort. Therefore in this case, the uncertainty is taken into account by calculating the accuracy z-score [8]:

$z_{a}^{\prime}=\frac{\bar{x}-X}{\sqrt{\sigma_{p}^{2}+u^{2}}}$

where:

$\mathrm{z}_{\mathrm{a}}^{\prime}=$ accuracy $\mathrm{z}$-score taking into account the uncertainty of the consensus value;

$\bar{x}=$ result of the laboratory;

$X=$ consensus value;

$\sigma_{\mathrm{p}}=$ standard deviation for proficiency assessment;

$\mathrm{u}=$ uncertainty of the consensus value. 


\section{$4 \quad$ Results}

A total of 19 of the 20 participants submitted results. An overview of the applied methods by the participants is presented in Annex 4. Not all laboratories reported the method used. Of the reported methods for dioxins and PCBs most involve an established automated or manual clean-up followed by GC-HRMS. Laboratories which only analysed ndl-PCB reported a wider range of clean-up methods, internal standards and detectors. Within the PT all these methods performed similar.

Please double click the icons below for an overview of the reported concentrations by the participants for materials $A, B$ and $C$. Results which were reported with smaller than values $('<$ ') were changed to the corresponding detection limits.
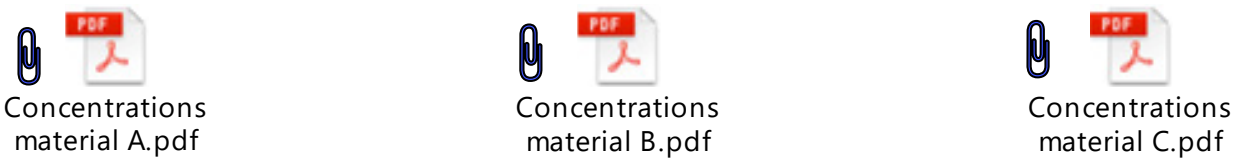

Please double click for an overview of the z-scores for materials A, B and C:
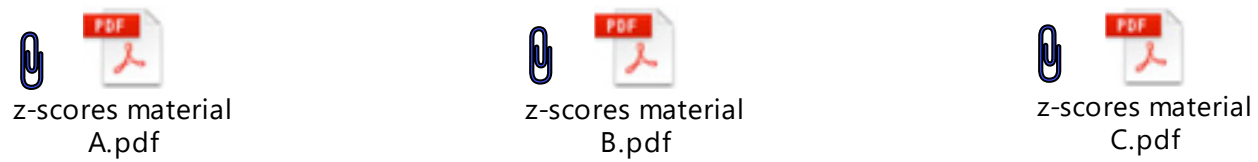

Double click for the graphical presentations of the z-scores for materials A, B and C. A short overview of the results is presented in Table 4.
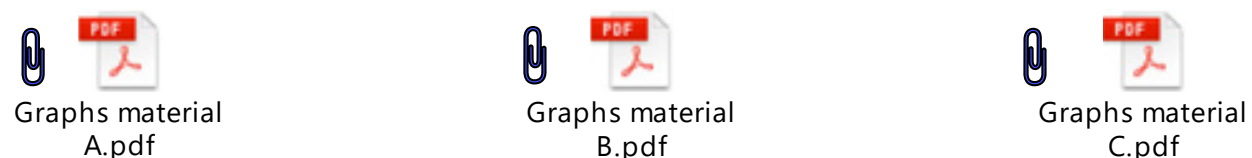

A total of 2091 z-scores were calculated. $z_{a}$-scores were calculated for all congeners in material A, for 28 of the 35 congeners in material $B$ and for 31 of the 35 congeners in material $C$. Not all congeners could be statistically evaluated due to a high uncertainty ( $\$ 3.2)$ or due to the fact that more than $1 / 3$ of the results was <LOQ (this is a protocol applied by the European Union Reference Laboratory). Three congeners in material $B$ and one congener in material $C$ could not be statistically evaluated due to a high uncertainty and four and three congeners in materials $B$ and $C$ respectively due to too many results $<$ LOQ.

Table 4 gives an overview of the performance of z-scores outside the -2 to 2 range for each participant. 
Table 4 Overview performance, number of $\mid z$-scores $\mid>2$.

\begin{tabular}{|c|c|c|c|c|c|c|}
\hline \multirow[b]{2}{*}{ Lab } & \multicolumn{2}{|c|}{ Material A } & \multicolumn{2}{|c|}{ Material B } & \multicolumn{2}{|c|}{ Material C } \\
\hline & sum-values* & $\begin{array}{l}\text { individual } \\
\text { compounds }\end{array}$ & sum-values* & $\begin{array}{l}\text { Individual } \\
\text { compounds }\end{array}$ & sum-values* & $\begin{array}{l}\text { Individual } \\
\text { Compounds }\end{array}$ \\
\hline PT173 & & & 3 & 1 & & 2 \\
\hline PT174 & & & & 1 & & \\
\hline PT176 & & 1 & & & & \\
\hline \multicolumn{7}{|l|}{ PT177 } \\
\hline PT178 & & 1 & 5 & 4 & & 3 \\
\hline PT179 & & 7 & & 7 & 3 & 7 \\
\hline PT184 & & & & 2 & & 1 \\
\hline PT185 & & 8 & 2 & 8 & 4 & 13 \\
\hline PT186 & & 3 & & 3 & & 5 \\
\hline PT187 & & 2 & & 5 & & \\
\hline PT188 & & & & 1 & & 3 \\
\hline PT189 & & & & 2 & 2 & 3 \\
\hline PT190 & & 3 & & 3 & & 2 \\
\hline PT191 & & & & & 3 & 2 \\
\hline
\end{tabular}

*WHO-PCDD/F-PCB, WHO-PCDD/F-TEQ, WHO-PCB-TEQ, sum NDL-PCB

A total of 193 z-scores > |2| was reported on a total of 2091 z-scores (9\%). For material A 53 z-scores > $|2|$ were reported (6\%), for material B $72(10 \%)$ and for material C 68 (9\%). For upperbound sum-values (WHO-PCDD/F-PCB, WHO-PCDD/F-TEQ, WHO-PCB-TEQ and sum NDL-PCB) 1 , 4 and 5 z-scores $>|2|$ were reported for materials $A, B$ and $C$ respectively.

In Table 5 the consensus values are presented.

Table 5 Consensus values.

\begin{tabular}{lccc} 
& Material A & Material B & \\
Dioxins in pg TEQ/g & 1.34 & 0.45 & 0.53 \\
\hline Dioxin-like PCBs in pg TEQ/g & 0.36 & 0.76 & 0.35 \\
\hline Dioxins and dioxin-like PCBs in pg TEQ/g & 1.69 & 1.19 & 0.89 \\
\hline Non-dioxin-like PCBs in ng/g & 9.0 & 24 & 8.8 \\
\hline
\end{tabular}

The results for the number of exceedings of the maximum level and/or action threshold (Table 1) based on the consensus values for each material reported by the participants are shown in Table 6 .

Table 6 Maximum level and action thresholds exceeded, based on consensus values.

\begin{tabular}{|c|c|c|c|c|c|c|}
\hline \multirow[b]{2}{*}{ Compound } & \multicolumn{2}{|c|}{ Material A } & \multicolumn{2}{|c|}{ Material B } & \multicolumn{2}{|c|}{ Material C } \\
\hline & $\begin{array}{c}\text { Maximum } \\
\text { level } \\
\text { exceeded? }\end{array}$ & $\begin{array}{l}\text { Action } \\
\text { threshold } \\
\text { exceeded? }\end{array}$ & $\begin{array}{c}\text { Maximum } \\
\text { level } \\
\text { exceeded? }\end{array}$ & $\begin{array}{l}\text { Action } \\
\text { threshold } \\
\text { exceeded? }\end{array}$ & $\begin{array}{c}\text { Maximum } \\
\text { level } \\
\text { exceeded? }\end{array}$ & $\begin{array}{c}\text { Action } \\
\text { threshold } \\
\text { exceeded? }\end{array}$ \\
\hline Dioxins & yes & yes & no & no & no & yes \\
\hline Dioxin-like PCBs & & no & & yes & & no \\
\hline Non-dioxin-like PCBs & no & & yes & & no & \\
\hline
\end{tabular}


The conclusions from the participants regarding exceedings of the maximum limits and/or action thresholds are presented in Table 7. Results must be reported according to Commission Regulation 152/2009 [13]. The green and red numbers in Table 7 below are based on the consensus values, not on the individual upperbound concentrations. Not all participants answered these questions in the webapplication.

Explanation for dioxins in material A: 11 participants correctly (green) reported the exceeding of the maximum level for dioxins in material $A$ and 2 participants incorrectly (red) reported the exceeding of the maximum level for dioxins.

Please note: Numbers in red do not indicate that individual participants wrongfully reported a sample compliant or non compliant. For example: the consensus value for dioxins in material $C$ is $0.53 \mathrm{pg}$ $\mathrm{TEQ} / \mathrm{g}$, which is close to the action threshold of $0.50 \mathrm{pg} T E Q / \mathrm{g}$. Some participants reported results below $0.50 \mathrm{pg} \mathrm{TEQ} / \mathrm{g}$, some above. However, in some cases participants truly reported incorrect results related to the (non)-compliancy of the sample.

Table 7 Conclusions from participants about exceeding maximum level and action threshold.

\begin{tabular}{|c|c|c|c|c|c|c|}
\hline \multirow[t]{2}{*}{ \# labs } & \multicolumn{2}{|c|}{ Material A } & \multicolumn{2}{|c|}{ Material B } & \multicolumn{2}{|c|}{ Material B } \\
\hline & $\begin{array}{c}\text { Maximum } \\
\text { level } \\
\text { exceeded? }\end{array}$ & $\begin{array}{c}\text { Action } \\
\text { threshold } \\
\text { exceeded? }\end{array}$ & $\begin{array}{c}\text { Maximum } \\
\text { level } \\
\text { exceeded? }\end{array}$ & $\begin{array}{c}\text { Action } \\
\text { threshold } \\
\text { exceeded? }\end{array}$ & $\begin{array}{c}\text { Maximum } \\
\text { level } \\
\text { exceeded? }\end{array}$ & $\begin{array}{c}\text { Action } \\
\text { threshold } \\
\text { exceeded? }\end{array}$ \\
\hline \multicolumn{7}{|l|}{ Dioxins in pg TEQ/g } \\
\hline yes & 11 & 10 & - & 1 & 0 & 3 \\
\hline \multicolumn{7}{|l|}{ Dioxin-like PCBs } \\
\hline yes & & 1 & & 9 & & 0 \\
\hline no & & 11 & & 3 & & 12 \\
\hline \multicolumn{7}{|l|}{ Dioxins and dioxin-like PCBs } \\
\hline yes & 1 & & 11 & & 1 & \\
\hline no & 13 & & 3 & & 11 & \\
\hline
\end{tabular}




\section{$5 \quad$ Conclusions}

Based on the results of this proficiency test it can be concluded that:

- Of a possible 2091 z-scores 193 results were questionable/unsatisfactory (9\%), of which 53 (6\%) in material A, $72(10 \%)$ in material B and $68(9 \%)$ in material C.

- For the dioxins $11 \%$ of all results was questionable/unsatisfactory, for dl-PCBs $8 \%$ and for ndl-PCBs $8 \%$.

- All congeneners of material A could be statistically evaluated, 28 out of 35 congeners in material B could be evaluated and 31 out of 35 for material $C$.

- Two (PT177 and PT180) out of 19 participants reported satisfactory results for all values (sumvalues and individual compounds).

- Another ten participants (PT172, PT174, PT175, PT176, PT182, PT184, PT186, PT187, PT188 and PT190) reported satisfactory results for the sum-values. 


\section{References}

1 Council directive 93/99/EEC of 29 October 1993 on the subject of additional measures concerning the official control of foodstuffs. Off J Eur Commun L 290, 24/11/1993, 0014 - 0017.

2 ISO/IEC 17025:2005(E). 2005. General Requirements for the Competence of Calibration and Testing Laboratories.

3 ISO/IEC 17043:2010. 2010. Conformity assessment - General requirements for Proficiency Testing.

4 Directive 2002/32/EC of the European Parliament and of the Council of 7 May 2002 on undesirable substances in animal feed.

5 SOPA0989 - De bereiding van referentiematerialen en referentiemonsters - RIKILT.

6 Commission Decision 2002/657/EC. 12 August 2002. Implementing Council Directive 96/23/EC concerning the performance of analytical methods and the interpretation of results. Off J Eur Commun L 221:67A-76A.

7 Thompson M, Ellison SL, Wood R. 2006. The International Harmonized Protocol for the Proficiency Testing of Analytical Chemistry Laboratories. Pure Appl. Chem. 78(1):145-196.

8 ISO 13528:2015. 2015. Statistical methods for use in proficiency testing by interlaboratory comparison.

9 Thompson M. 2000. Recent trends in inter-laboratory precision at ppb and sub-ppb concentrations in relation to fitness for purpose criteria in proficiency testing. Analyst. 125:385-386.

10 McClure FD. 1990. Design and analysis of qualitative collaborative studies: minimum collaborative program. JAOAC Int. 73 (6): 953-960.

11 Analytical Methods Committee. 1989. Robust statistics - How not to reject outliers Part 1. Basic concepts. Analyst 114:1693-1697.

12 Analytical Methods Committee. 1989. Robust statistics - How not to reject outliers Part 2. Inter-laboratory trials. Analyst. 114:1699-1702.

13 Commission Regulation (EC) 152/2009 of 27 January 2009 laying down the methods of sampling and analysis for the official control of feed. 


\section{Annex 1 Codification of the samples}

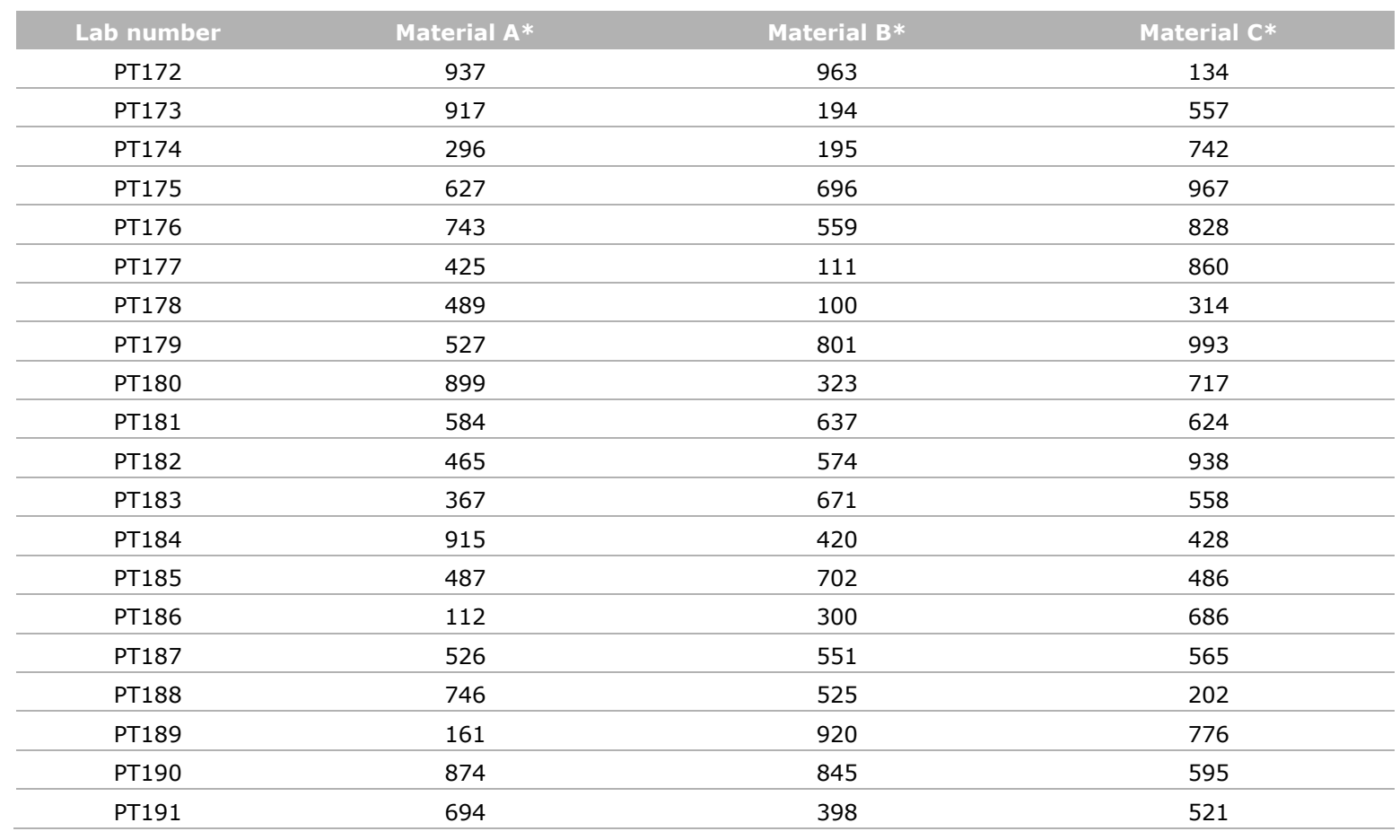

* All sample codes start with DIOX/2018/feed oil/ 


\section{Annex 2 Statistical evaluation of homogeneity data}

\begin{tabular}{|c|c|c|}
\hline & PCB 153 in $\mathrm{m}$ & \\
\hline Sample number & Replicate 1 & Replicate 2 \\
\hline Hom/A001 & 5.1 & 4.9 \\
\hline Hom/A002 & 4.8 & 5.0 \\
\hline Hom/A003 & outlier & outlier \\
\hline Hom/A004 & 5.1 & 5.0 \\
\hline Hom/A005 & 5.0 & 5.0 \\
\hline Hom/A006 & 5.0 & 4.9 \\
\hline Hom/A007 & 5.1 & 5.0 \\
\hline Hom/A008 & 5.1 & 5.0 \\
\hline Hom/A009 & 5.0 & 4.8 \\
\hline Hom/A010 & 5.0 & 4.9 \\
\hline Grand mean & 5.0 & \\
\hline \multicolumn{3}{|l|}{ Cochran's test } \\
\hline C & 0.313 & \\
\hline$C_{\text {crit }}$ & 0.638 & \\
\hline $\mathrm{C}<\mathrm{C}_{\text {crit }}$ ? & NO OUTLIERS & \\
\hline Target $\mathrm{s}=\sigma_{\mathrm{p}}$ & Horwitz: 1.10 & \\
\hline$s_{x}$ & 0.06 & \\
\hline $\mathrm{s}_{\mathrm{w}}$ & 0.09 & \\
\hline $\mathrm{s}_{\mathrm{s}}$ & 0.00 & \\
\hline Critial $=0.3 \sigma_{\mathrm{P}}$ & 0.33 & \\
\hline $\mathrm{S}_{\mathrm{s}}<$ critical? & ACCEPTED & \\
\hline $\mathrm{S}_{\mathrm{w}}<0.5 \sigma_{\mathrm{p}} ?$ & ACCEPTED & \\
\hline
\end{tabular}

\begin{tabular}{|c|c|c|}
\hline & PCB 153 in $\mathrm{m}$ & \\
\hline Sample number & Replicate 1 & Replicate 2 \\
\hline Hom/B001 & 20.1 & 20.2 \\
\hline Hom/B002 & 19.9 & 20.1 \\
\hline Hom/B003 & 20.1 & 19.1 \\
\hline Hom/B004 & 20.2 & 20.2 \\
\hline Hom/B005 & 19.8 & 19.6 \\
\hline Hom/B006 & 20.4 & 20.0 \\
\hline Hom/B007 & 20.9 & 20.3 \\
\hline Hom/B008 & 20.5 & 19.7 \\
\hline Hom/B009 & 19.9 & 19.9 \\
\hline Hom/B010 & 21.0 & 20.2 \\
\hline Grand mean & 20.1 & \\
\hline \multicolumn{3}{|l|}{ Cochran's test } \\
\hline C & 0.346 & \\
\hline $\mathrm{C}_{\text {crit }}$ & 0.602 & \\
\hline $\mathrm{C}<\mathrm{C}_{\text {crit }}$ ? & NO OUTLIERS & \\
\hline Target $\mathrm{s}=\sigma_{\mathrm{p}}$ & Horwitz: 4.42 & \\
\hline$s_{x}$ & 0.33 & \\
\hline $\mathrm{S}_{\mathrm{w}}$ & 0.38 & \\
\hline $\mathrm{Ss}_{\mathrm{s}}$ & 0.19 & \\
\hline Critial $=0.3 \sigma_{\mathrm{P}}$ & 1.33 & \\
\hline $\mathrm{S}_{\mathrm{s}}<$ critical? & ACCEPTED & \\
\hline $\mathrm{S}_{\mathrm{W}}<0.5 \sigma_{\mathrm{P}} ?$ & ACCEPTED & \\
\hline
\end{tabular}




\section{PCB 153 in material C ( $\mu g / \mathrm{kg})$}

\begin{tabular}{|c|c|c|}
\hline Sample number & Replicate 1 & Replicate 2 \\
\hline Hom/C001 & 4.3 & 4.2 \\
\hline $\mathrm{Hom} / \mathrm{C002}$ & 4.1 & 4.4 \\
\hline $\mathrm{Hom} / \mathrm{C003}$ & 4.4 & 4.4 \\
\hline $\mathrm{Hom} / \mathrm{COO} 4$ & 4.3 & 4.3 \\
\hline Hom/C005 & 4.6 & 4.4 \\
\hline Hom/C006 & 4.2 & 4.3 \\
\hline $\mathrm{Hom} / \mathrm{COO7}$ & 4.3 & 4.4 \\
\hline Hom/C008 & 4.4 & 4.4 \\
\hline Hom/C009 & 4.3 & 4.3 \\
\hline $\mathrm{Hom} / \mathrm{C} 010$ & 4.2 & 4.3 \\
\hline Grand mean & 4.3 & \\
\hline \multicolumn{3}{|l|}{ Cochran's test } \\
\hline C & 0.543 & \\
\hline$C_{\text {crit }}$ & 0.602 & \\
\hline $\mathrm{C}<\mathrm{C}_{\text {crit }}$ ? & NO OUTLIERS & \\
\hline Target $\mathrm{s}=\sigma_{\mathrm{P}}$ & Horwitz: 0.95 & \\
\hline$S_{x}$ & 0.07 & \\
\hline $\mathrm{S}_{\mathrm{w}}$ & 0.10 & \\
\hline $\mathrm{S}_{\mathrm{s}}$ & 0.00 & \\
\hline Critial $=0.3 \sigma_{\mathrm{P}}$ & 0.28 & \\
\hline $\mathrm{s}_{\mathrm{s}}<$ critical? & ACCEPTED & \\
\hline$S_{w}<0.5 \sigma_{p} ?$ & ACCEPTED & \\
\hline \multicolumn{3}{|c|}{$\mathrm{S}_{\mathrm{x}}=$ standard deviation of the sample averages. } \\
\hline \multicolumn{3}{|c|}{$\mathrm{s}_{\mathrm{w}}=$ within-sample standard deviation. } \\
\hline \multicolumn{3}{|c|}{$\mathrm{S}_{\mathrm{s}}=$ between-sample standard deviation. } \\
\hline
\end{tabular}




\section{Annex 3 Instruction letter}

WAGENINGEN

UNIVERSITY \& RESEARCH

Dear participant,

Thank you very much for your interest in the proficiency study for the analysis of dioxins and PCBs in feed oil. Hereby I send you a parcel containing three randomly coded samples, one sample containing $15 \mathrm{~g}$ of feed oil and two samples containing $10 \mathrm{~g}$ of feed oil.

Please fill out the accompanying acknowledgement of receipt form and return it immediately upon receipt of the samples, preferably by e-mail (pt.rikilt@wur.nl)

Instructions:

- After arrival store the samples according to your laboratory's procedures and treat the test material as if it was a sample for routine analysis.

- Please carry out a single analysis for each sample. Report one result and not an average of multiple measurements.

- $\quad$ Report all results relative to a feed with a moisure content of $12 \%$ (assuming $0 \%$ moisture in the sample).

- $\quad$ The deadline for submitting test-results for this test is March 5th 2018.

- $\quad$ Please use the web application for entering your results (https://arlwebshop.wurin/apex/f?p=307:LOGIN). Information about the use of this web application was sent to you earlier by e-mail.

- Results for compounds reported with smaller than values $(<)$ will be changed to the corresponding detection limits.

- Your username is:

- Your password is:

- Your lab code to enter this proficiency test is:

- $\quad$ Please inform us about your applied method and detection technique (via the web application).

Please contact me if you have any questions or need any assistance.

With kind regards,

D. Pereloom

D.P.K.H. Pereboom

pt.rikilt@wur.nl

RIKILT

san

January 29, 2018

sunecr

Proficiency test diaxins an PCBs in foed ol

oue katerac

1801673/RuK

PETIN ADENSS

P.O. Box 230

6700 AE WAGENINGEN

The Netherlands

usmoner neeness

Wsgeningen Compus

Bullding 123

Akkermasisbos 2

6708 WB WAGENENGEN

มะเะตั

www.wur.n//rikalt

Coc mimate
09098104

mavecio an

D.P.K.H. Pereboom

menewosi

+31 (0)614323017

amili

pt.rilkitewur.ni 


\section{Annex 4 Overview of the applied methods for dioxins and (non)dioxin- like PCBs}

\begin{tabular}{|c|c|c|c|}
\hline Lab & Sample purificiation & Internal standard & Detection method \\
\hline PT172 & dilution in Hexane, cleanup with H2SO4-silica column, fractionation in PCDDF and PCB with Alox, cleanup of PCDDF with florisil & $13 \mathrm{C}$ for each compound & GC-HRMS \\
\hline PT173 & cold extraction, clean up with silica gel, fractionation to aluminium oxide & isotopic marked 13C12-standard & HRGC/HRMS \\
\hline PT174 & - Silica/sulfuric acid column - Florisil column (NDL-PCB) - Alumina column - Carbon column & $\begin{array}{l}\text { PCDD/F: } 15 \text { labeled internal standard } \\
2 \text { labeled recovery standard EPA } \\
1613 \text { DL-PCB: } 12 \text { labeled internal } \\
\text { standard } 3 \text { labeled recovery standard } \\
\text { EPA } 1668 \text { NDL-PCB: } 6 \text { labeled } \\
\text { internal standard } 1 \text { labeled recovery } \\
\text { standa }\end{array}$ & $\begin{array}{l}\text { GC-MS PCDD/F-DL-PCB: } \\
\text { GC inj: splitless Injected } \\
\text { vol: } 2 \mu \mathrm{L} \text { GC } \\
\text { Separation:DB-5ms } \\
\text { Detector: HRMS GC-MS } \\
\text { NDL-PCBs: GC inj: splitless } \\
\text { Injected vol: } 1 \mu \mathrm{L} \text { GC } \\
\text { Separation:DB-XLB } \\
\text { Detector: HRMS }\end{array}$ \\
\hline PT175 & soxtherm and Miura clean-up system & Yes, all compounds labeled. & GC-HRMS \\
\hline PT176 & Extraction: dissolved in organic solvent Clean-up: - GPC -Silica sulphuric acid column - Florisil column - Carbon column & $\begin{array}{l}\text { Isotope dilution } 13 \mathrm{C} \text {-labelled internal } \\
\text { standards for all relevant congeners }\end{array}$ & GC-HRMS \\
\hline PT177 & clean up: 3 columns: sulphuric acid, Alox and active carbon & $\begin{array}{l}13 \mathrm{C} \text { labelled internal standard for } \\
\text { each congener }\end{array}$ & HRGC-HRMS \\
\hline PT178 & L/L, NP-Coloum & isoptope-marked & HR-GC/MS \\
\hline PT179 & Hot extraction method (twisselman method) Clean-up: Automatic Power-prep system for clean-up of samples & $\begin{array}{l}\text { labelled Mixture of Dioxins/Furans, } \\
\text { DL-PCB and NDL-PCB }\end{array}$ & $\begin{array}{l}\text { HRGC-HRMS (isotope } \\
\text { dilution Method) }\end{array}$ \\
\hline PT180 & $\begin{array}{l}\text { No extraction First Silica:H2SO4-treatment. Followed by PowerPrep (Mulitlayer silica, alumina and carbon).For DF and noPCB- } \\
\text { fraction followed by an additional small multilayer silica column }\end{array}$ & 13C-labelled analogues & HRGC-HMRS \\
\hline \multicolumn{4}{|l|}{ PT181 } \\
\hline PT182 & $\begin{array}{l}\text { Dissolve in Cycloexane/Ethyl Acetate, gel permeation chromatography, removal of solvent, dissolve in Hexane, column } \\
\text { chromatography, removal of solvent, dissolv for detection }\end{array}$ & $\begin{array}{l}\text { 13C-PCB-28, 13C-PCB-52, 13C-PCB- } \\
\text { 101, 13C-PCB-138, 13C-PCB-153, } \\
13 \mathrm{C}-\mathrm{PCB}-180\end{array}$ & GC-MS \\
\hline 「183 & & & \\
\hline
\end{tabular}


PT185 No extraction was needed.

mono-ortho and indicator PCBS: Acid silica column and acid silica/alumina column
Lab Sample purificiation

Internal standard

Toluene solutions containing a

mixture of the $13 \mathrm{C} 12$ isomers of all

the $17 \mathrm{PCDD} / \mathrm{F}$ congeners except

OCDF, the four $13 \mathrm{C} 12$ non-ortho

PCBs, the eight $13 \mathrm{C} 12$ mono-ortho

PCBs and $13 C 12$ PCB 52 and 101 for

indicator PCBs

PT186

PT187 Powerprep Cleanup

PT188 Automatic clean-up

PT189 Extraction accord. to EURL-FV method EURL-FV (2012-M6)for pesticides in olive oil 1,5g of oil - Addition of Hexane and ACN cleanup using C18 SPE cartridge or Zsep+

PT190 Silicagel impregnated with sulfuric acid, alox, activated charcoal

PT191 clean up : acid silica/aluminium oxide/Na2SO4
13Clabelled

$13 \mathrm{C}$ isoptopes

GCHRMS

triphenylphosphate (TPP)

HRMS-HRGCMS

GC-MS/MS

C-13 labeled for each component

PCB155

GCHRMS

GCMS
Detection method

GC-HRMS Spectrometry 
RIKILT Wageningen University \& Research P.O. Box 230

6700 AE Wageningen

The Netherlands

$\mathrm{T}+31(0) 317480256$

www.wur.eu/rikilt

RIKILT report 2018.007 (version 2)
The mission of Wageningen University \& Research is "To explore the potential of nature to improve the quality of life". Under the banner Wageningen University \& Research, Wageningen University and the specialised research institutes of the Wageningen Research Foundation have joined forces in contributing to finding solutions to important questions in the domain of healthy food and living environment. With its roughly 30 branches, 5,000 employees and 10,000 students, Wageningen University \& Research is one of the leading organisations in its domain. The unique Wageningen approach lies in its integrated approach to issues and the collaboration between different disciplines. 



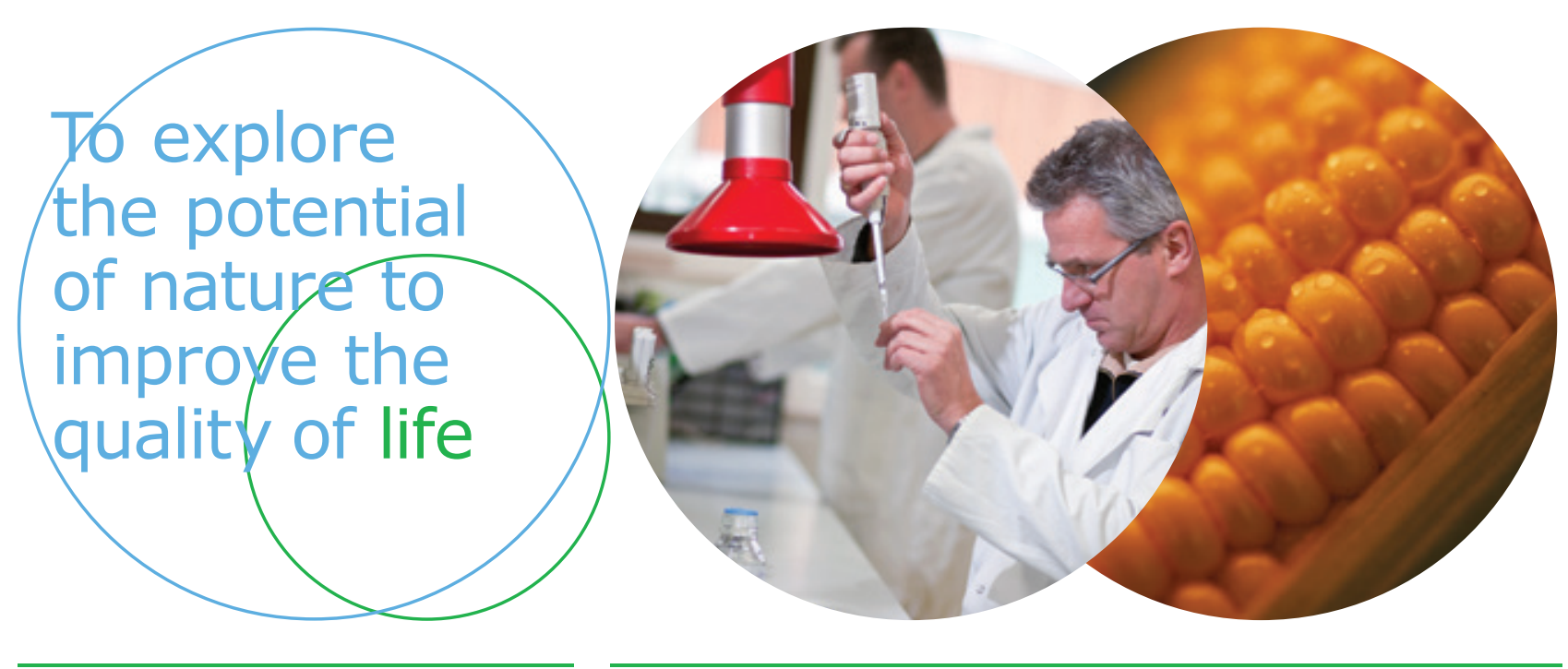

RIKILT Wageningen University \& Research P.O. Box 230

6700 AE Wageningen

The Netherlands

T +31 (0)317480256

www.wur.eu/rikilt

Report 2018.007 (version 2)
The mission of Wageningen University \& Research is "To explore the potential of nature to improve the quality of life". Under the banner Wageningen University \& Research, Wageningen University and the specialised research institutes of the Wageningen Research Foundation have joined forces in contributing to inding solutions to important questions in the domain of healthy food and living environment. With its roughly 30 branches, 5,000 employees and 10,000 students, Wageningen University \& Research is one of the leading organisations in its domain. The unique Wageningen approach lies in its integrated approach to issues and the collaboration between different disciplines. 